\title{
Controle van \\ jaarrekeningen door accountants
}

\author{
Een economisch gedragsmodel
}

Drs. M. van Dijk

\section{Inleiding ${ }^{1}$}

In de literatuur is veel geschreven over de wijze waarop accountants de controle van jaarrekeningen dienen uit te voeren. Uitgangspunt hierbij is dat de controle zodanig dient te geschieden dat gecontroleerde en goedgekeurde jaarrekeningen geen materiële fouten bevatten. Om dit te bereiken dient aan twee voorwaarden te worden voldaan. Allereerst dient de controle zodanig te worden uitgevoerd dat materiële fouten die in de jaarrekeningen aanwezig zijn ook worden ontdekt (de controle dient vaktechnisch correct uitgevoerd te worden). Verder dienen alle (materiële) fouten die bij de controle worden ontdekt ook gecorrigeerd te worden, ook als het management zich hiertegen zou verzetten (de accountant dient zich onafhankelijk op te stellen). Indien het management niet bereid is de fouten te corrigeren, dient de accountant de jaarrekening af te keuren.

Uit empirisch onderzoek blijkt echter dat in de praktijk het gedrag van accountants vaak afwijkt van hetgeen in de literatuur wordt voorgeschreven. Zo blijkt uit diverse studies dat door accountants gecontroleerde (en goedgekeurde) jaarrekeningen vaak nog materiële fouten bevatten (zie bijv. St. Pierre en Anderson, 1984). Verder blijkt uit een groot aantal onderzoeken dat veel accountants onder druk van het management bereid zijn materiële fouten in de jaarrekening te accepteren (zie bijv. Knapp, 1985, Farmer et al, 1987 en Van de Poel en Schilder, 1990). Over de oorzaken van de afwijkingen tussen literatuur en praktijk is nog weinig bekend.

In dit artikel zullen we een model ontwikkelen dat aangeeft hoe accountants zich zullen gedragen als de partijen die bij de jaarrekeningcontrole zijn betrokken (ondernemingen, accountantsmaatschappen en accountants) zich uitsluitend laten leiden door economische voordelen op korte termijn en waarmee een aantal van de afwijkingen tussen de normatieve literatuur en het gedrag van accountants in de praktijk kunnen worden verklaard. Uiteraard zullen in de praktijk ook andere overwegingen (zoals bijvoorbeeld de reputatie van accountantsmaatschap en accountant) een rol spelen en het is zelfs heel goed mogelijk dat deze overwegingen belangrijker zijn dan de door ons genoemde factoren. Uit empirisch onderzoek blijkt echter wel dat economische voordelen op korte termijn in de praktijk vaak mede een rol spelen.

Het artikel is als volgt opgebouwd. In paragraaf 2 zullen we kort aangeven van welke veronderstellingen we uitgaan inzake de diverse partijen die bij de jaarrekeningcontrole

Drs. M. van Dijk heeft bedrijfseconomie en accountancy gestudeerd aan de Erasmus Universiteit Rotterdam. Hii is verbonden aan de Economische Faculteit van de Rijksuniversiteit Groningen. 
zijn betrokken. In paragraaf 3 zullen we nagaan hoe accountantsmaatschappen klanten verwerven en welke gevolgen dit heeft voor het gedrag van accountants. In paragraaf 4 zullen we aandacht schenken aan de uitvoering van de jaarrekeningcontrole en in paragraaf 5 aan de onafhankelijkheid van accountants. In paragraaf 6 zullen we het gedragsmodel samenvatten en de belangrijkste verschillen met de normatieve literatuur aangeven. In paragraaf 7 zullen we tenslotte kort aandacht schenken aan enige empirische onderzoekuitkomsten, waarna we in paragraaf 8 onze conclusies zullen samenvatten.

\section{Veronderstellingen inzake de diverse partijen die bij de jaarrekeningcontrole zijn betrokken}

Ondernemingen. Ondernemingen worden bestuurd door managers die een doorslaggevende invloed hebben op de keuze van de accountantsmaatschap die de jaarrekening van de onderneming controleert. Deze managers worden door de eigenaren beoordeeld op grond van de financiële resultaten van de onderneming, zoals vermeld in de jaarrekening. Managers hebben er belang bij dat de gepresenteerde jaarrekening leidt tot een gunstige beoordeling door de eigenaren van de onderneming. Dit heeft tot gevolg dat managers bij slechte ondernemingsresultaten zullen trachten deze resultaten in de jaarrekening gunstiger voor te stellen, bijvoorbeeld door het opnemen van te lage voorzieningen of door het wijzigen van de waarderingsgrondslagen. ${ }^{2} \mathrm{Bij}$ zeer goede ondernemingsresultaten zal het management trachten de resultaten in de jaarrekening juist ongunstiger voor te stellen (bijvoorbeeld door het opnemen van te hoge voorzieningen), omdat hierdoor wordt voorkomen dat bij de eigenaren van de onderneming te rooskleurige verwachtingen ontstaan omtrent de toekomstige resultaten en omdat hierdoor geheime reserves worden gecreëerd waaruit in de toekomst bij tegenvallende resultaten geput kan worden.
Gebruikers jaarrekeningen. Jaarrekeningen geven inzicht in de financiële resultaten van de onderneming en worden aangeboden aan de eigenaren van de onderneming. In sommige gevallen (afhankelijk van onder meer omvang en rechtsvorm van de onderneming) wordt de jaarrekening ook gepubliceerd, zodat iedere geïnteresseerde er kennis van kan nemen. Gebruikers van jaarrekeningen baseren vaak beslissingen (bijv. om aandelen van de onderneming te kopen of om aan de onderneming een krediet te verlenen) op informatie uit de jaarrekening en hebben er dus belang bij dat deze informatie juist is. Als blijkt dat een jaarrekening die door een accountant is goedgekeurd materiële fouten bevat, dan zal de gebruiker trachten zijn schade op de maatschap te verhalen door het indienen van een schadeclaim. Vooral als op grond van een onjuiste jaarrekening de onderneming door derden is overgenomen, kunnen deze schadeclaims zeer groot zijn.

Accountantsmaatschappen en accountants. Accountantsmaatschappen zijn commerciële instellingen die streven naar maximalisatie van omzet en winst. Dit heeft tot gevolg dat zij de bij de maatschap werkzame accountants zullen beoordelen naar de mate waarin zij bijdragen tot de winst en omzet van de maatschap, waarbij vooral de volgende aspecten van belang zijn:

- verwerving van nieuwe klanten.

Nieuwe klanten leveren niet alleen opbrengsten op uit de jaarrekeningcontrole, maar vaak ook uit advieswerkzaamheden, hetgeen tot gevolg heeft dat verwerving van nieuwe klanten een zeer positieve invloed heeft op de beoordeling van accountants.

- verlies van klanten.

Omgekeerd heeft verlies van klanten een negatieve invloed op de beoordeling van accountants omdat hierdoor voor de maatschap opbrengsten verloren gaan. De maatschap gaat er (impliciet) van uit dat een accountant met goede sociale vaardigheden in staat is verlies van klanten te voorkomen. 


\section{MAB}

- winstgevendheid van opdrachten.

Van accountants wordt verwacht dat zij er door een efficiënte uitvoering van de controle voor zorgen dat opdrachten voor de maatschap winst opleveren.

schadeclaims.

Als blijkt dat goedgekeurde jaarrekeningen materiële fouten bevatten, dan kan dit tot gevolg hebben dat door gebruikers van jaarrekeningen schadeclaims worden ingediend die voor de maatschap zeer hoge kosten met zich brengen. Schadeclaims hebben dan ook een zeer negatieve invloed op de beoordeling van de accountant die de jaarrekening heeft goedgekeurd.

\section{Verwerving van nieuwe klanten}

Bij de keuze van de accountantsmaatschap die zal worden belast met de controle van de jaarrekening heeft het management van de onderneming er vooral belang bij dat de jaarrekening tegen zo laag mogelijke kosten wordt gecontroleerd omdat hierdoor de winst van de onderneming stijgt. Om dit te bereiken zal zij aan een aantal accountantsmaatschappen verzoeken een offerte uit te brengen, en de maatschap kiezen die bereid is de jaarrekening tegen de laagste prijs te controleren. Een probleem voor de maatschappen bij het uitbrengen van een offerte is dat het veelal niet mogelijk is een nauwkeurige raming te maken van de werkzaamheden die voor de controle van de jaarrekening nodig zijn. De redenen hiervan zijn:

- voor het vaststellen van de benodigde controlewerkzaamheden is een gedetailleerd onderzoek van de onderneming nodig. Zo'n onderzoek is echter tijdrovend en kostbaar. Omdat de maatschappen geen zekerheid hebben dat zij de controle-opdracht ook zullen verwerven, zullen zij terughoudend zijn met het uitvoeren van zo'n onderzoek. Ook de onderneming zal veelal bezwaren hebben tegen gedetailleerde en tijdrovende onderzoeken door meerdere maatschappen.
- ook na een gedetailleerd onderzoek van de onderneming is een nauwkeurige raming van de benodigde controlewerkzaamheden veelal zeer moeilijk. Welke werkzaamheden voor een goede jaarrekeningcontrole nodig zijn blijkt voor een belangrijk deel pas tijdens de uitvoering van de controle. Ook uit empirisch onderzoek blijkt dat accountants, zelfs bij een gedetailleerde kennis van de te controleren onderneming, veelal niet in staat zijn een betrouwbare raming van de benodigde controlewerkzaamheden te maken. ${ }^{3}$

Welke gevolgen heeft dit nu voor het gedrag van een opportunistisch ingestelde accountant?

Aangezien een nauwkeurige raming van de benodigde controlewerkzaamheden niet mogelijk is, zal de accountant proberen een globale raming van de controlekosten te maken aan de hand van snel en eenvoudig verkrijgbare informatie, zoals de omvang van de onderneming (omzet, aantal werknemers, omvang activa etc.), de aard van de onderneming en de complexiteit van de onderneming (aanwezigheid dochterondernemingen, buitenlandse activiteiten etc.). Verder geeft ook het bedrag dat door de vorige accountantsmaatschap voor de controle van de jaarrekeningen in rekening werd gebracht vaak een indicatie over de controlekosten.

Omdat verwerving van nieuwe klanten een zeer positieve invloed heeft op zijn beoordeling, zal de accountant vervolgens trachten een concurrerende offerte voor de jaarrekeningcontrole uit te brengen die ertoe leidt dat de opdracht wordt verkregen. Omdat slechts een globale raming van de controlekosten beschikbaar is en het, zoals in het vervolg van dit artikel zal blijken, veelal mogelijk is om later de kosten van de controle zonder veel extra risico te beperken, zal de accountant om de opdracht te verkrijgen indien nodig bereid zijn een offerte uit te brengen die lager is dan de geraamde controlekosten. Bij het uitbrengen van de offerte zal de accountant rekening houden met de volgende factoren: 
- adviesmogelijkheden

Adviesopdrachten zijn veelal meer winstgevend dan controle-opdrachten. Naarmate de kans groter is dat uit verwerving van de klant adviesopdrachten zullen voortvloeien, zal de accountant bereid zijn een lagere offerte uit te brengen om de klant te verwerven.

- mate concurrentie tussen accountantsmaatschappen

Naarmate deze concurrentie groter is, zal een lagere offerte uitgebracht worden om de klant te verwerven.

\section{Uitvoering van de jaarrekeningcontrole}

Als een klant is verworven, dient jaarlijks haar jaarrekening gecontroleerd te worden. Volgens de in leerboeken, beroepsregels en controlerichtlijnen vastgelegde normen dient deze controle zodanig te worden uitgevoerd dat (materiële) fouten die in de jaarrekening aanwezig zijn, ook worden ontdekt. De uitvoering van de controle dient dus geheel bepaald te worden door vaktechnische overwegingen.

Bij de besluitvorming van een opportunistische accountant omtrent de uitvoering van de controle zullen echter vooral de volgende overwegingen een rol spelen:

- met de onderneming is voor de jaarrekeningcontrole een vaste prijs afgesproken. Deze prijs is niet gebaseerd op een nauwkeurige raming van de benodigde controlewerkzaamheden, maar is vooral bepaald door commerciële overwegingen en de wens nieuwe klanten te verwerven. Dit heeft tot gevolg dat het geenszins zeker is dat de prijs die voor de jaarrekeningcontrole is afgesproken voldoende zal zijn om de kosten van een (vaktechnisch) goede controle te dekken.

- van de accountant wordt verwacht dat hij de controle zo efficiënt uitvoert dat de opdracht voor de maatschap winst oplevert (hierop wordt hij ook beoordeeld). Dit heeft tot gevolg dat de accountant de neiging zal hebben de controlewerkzaamheden (en dus de controle- kosten) te beperken en in ieder geval zal proberen de controlekosten de afgesproken prijs niet te laten overschrijden.

- een beperking van de controlewerkzaamheden leidt echter tot een verhoogd risico dat (materiële) fouten in de jaarrekening niet worden ontdekt. Niet-ontdekte fouten in de jaarrekening leiden echter alleen tot een negatieve beoordeling van de accountant als deze fouten later door gebruikers van de jaarrekening worden ontdekt en leiden tot schadeclaims en rechtszaken. De kans dat dit gebeurt is vooral groot in de volgende situaties:

1 De jaarrekening wordt gepubliceerd.

Naarmate meer personen van de jaarrekening kennis kunnen nemen is de kans groter dat fouten in de jaarrekening worden ontdekt en dat schade ontstaat (die leiden tot schadeclaims) omdat beslissingen op een onjuiste jaarrekening worden gebaseerd.

2 De aandelen van de onderneming worden regelmatig verhandeld.

Kopers en verkopers van aandelen baseren hun beslissingen in belangrijke mate op informatie uit jaarrekeningen. Als de aandelen van de onderneming regelmatig worden verhandeld (zoals bijv. bij een beursonderneming), dan is de kans groter dat fouten in de jaarrekening schade veroorzaken bij kopers (en verkopers) van aandelen en daardoor leiden tot schadeclaims.

3 De onderneming staat in de publieke belangstelling.

Naarmate de onderneming meer in de belangstelling staat, zullen meer personen de jaarrekening lezen waardoor de kans groter wordt dat fouten in de jaarrekening worden ontdekt.

4 De onderneming wordt door derden overgenomen.

Fouten in de jaarrekening kunnen bij overname van de onderneming zeer grote schade tot gevolg hebben en daardoor leiden tot omvangrijke schadeclaims. De kans dat fouten in de jaarrekening door de overnemende partij worden ontdekt is zeer groot omdat deze na de overname immers.over alle informatie van de onderneming kan beschikken. 


\section{MAB}

5 De financiële positie van de onderneming is slecht.

Als de financiële positie van de onderneming slecht is dan zal het management vaak trachten het in de jaarrekening vermelde ondernemingsresultaat te flatteren door bijvoorbeeld het opnemen van te lage voorzieningen of het wijzigen van de waarderingsgrondslagen. Vooral als de onderneming dan later failliet gaat, is de kans zeer groot dat de maatschap met (grote) schadeclaims wordt geconfronteerd. Door het faillissement wordt voor iedere belanghebbende duidelijk dat de jaarrekening onjuist was en zullen de gedupeerde partijen trachten hun schade op de accountantsmaatschap te verhalen.

Welke gevolgen heeft dit voor het gedrag van een opportunistische accountant?

De accountant wordt beoordeeld op de winstgevendheid van zijn opdrachten en zal er dus naar streven de controlewerkzaamheden (controlekosten) te beperken. Beperking van de controle leidt echter tot een verhoogd risico dat fouten in de jaarrekening niet worden ontdekt. Dit heeft echter alleen negatieve gevolgen voor de accountant zelf als later wordt ontdekt dat de jaarrekening fouten bevatte en als dit leidt tot schadeclaims en rechtszaken. Omdat het negatieve effect van schadeclaims en rechtszaken zeer groot is, zal de accountant proberen het risico van schadeclaims en rechtszaken zo klein mogelijk te houden, zelfs als hierdoor de omvang van de controle zo sterk uitgebreid moet worden dat de opdracht verlies oplevert.

De accountant zal zich dus als volgt gedragen: 1 hij zal aan de hand van de hiervoor vermelde factoren (publikatie jaarrekening, kans overname onderneming etc.) het risico inschatten dat fouten in de jaarrekening leiden tot schadeclaims of rechtszaken.

2 naarmate dit risico door de accountant hoger wordt ingeschat, zal hij geneigd zijn de controlewerkzaamheden zo ver uit te breiden dat alle (materiële) fouten in de jaarrekening ook worden ontdekt, ook als dit tot gevolg heeft dat hierdoor de controlekosten hoger worden dan de opbrengst, en de opdracht verlies oplevert. ${ }^{4}$

3 naarmate het risico van schadeclaims en rechtszaken lager wordt ingeschat, zal de accountant meer de neiging hebben om de controlewerkzaamheden te beperken zodat meer winst wordt gemaakt. In ieder geval zal hij de controle zo ver beperken dat de kosten lager zijn dan de opbrengst, ook als hierdoor het risico van (materiële) fouten in de jaarrekening wordt vergroot. ${ }^{4}$

\section{Onafhankelijkheid accountant}

Tijdens de controle van de jaarrekening worden regelmatig fouten gevonden. Volgens de (normatieve) literatuur dient de accountant zich met betrekking tot deze fouten als volgt te gedragen. Als de gevonden fouten naar het oordeel van de accountant 'materieel' zijn, dan dienen ze in de jaarrekening gecorrigeerd te worden. Als het management van de onderneming druk uitoefent om correctie na te laten, dan dient de accountant hiervoor niet te bezwijken (hij dient zich onafhankelijk op te stellen). Als het management blijft weigeren de fouten te corrigeren, dan dient de accountant de jaarrekening af te keuren (door het geven van een afkeurende verklaring). ${ }^{5}$

Bij de besluitvorming van een opportunistisch ingestelde accountant zullen echter vooral de volgende overwegingen een rol spelen:

- Welke fouten wel of niet materieel zijn en welke correctie in de jaarrekening nodig is, is vaak een kwestie van subjectieve beoordeling die per accountant aanzienlijk kan verschillen (zie bijv. Van Manen, 1989).

- Het management van de onderneming heeft er vaak een groot belang bij dat fouten in de jaarrekening niet worden gecorrigeerd. Vooral als de financiële positie van de onderneming slecht is, zal het management zich verzetten tegen correcties (bijv. in de vorm van hogere voorzieningen) die tot gevolg hebben dat het fınanciële resultaat van de onderneming ver- 


\section{MAB}

der wordt verslechterd. Zij zal hierbij naar voren brengen dat de correcties niet objectief vastgesteld kunnen worden en in sterke mate afhankelijk zijn van de subjectieve beoordeling van de accountant.

- Als de accountant blijft eisen dat de jaarrekening wordt gecorrigeerd, zal het management de druk op de accountant verder vergroten door (openlijk of in bedekte termen) te dreigen de relatie met de maatschap te verbreken. Verlies van klanten is nadelig voor de maatschap, vooral als het een grote klant betreft, als de klant veel adviesopbrengsten oplevert en als de maatschap klein is. Verlies van klanten heeft een negatieve invloed op de beoordeling van de betreffende accountant, ook ats dit wordt veroorzaakt door een onredelijke opstelling van de klanten. De maatschap gaat er immers (impliciet) van uit dat een accountant met voldoende sociale vaardigheden en overtuigingskracht in staat is klanten van de redelijkheid van zijn opvattingen te overtuigen en daardoor verlies van klanten kan voorkomen.

- Als de accountant onder druk van het management fouten in de jaarrekening accepteert, dan heeft dit tot gevolg dat de accountant ten onrechte een onjuiste jaarrekening goedkeurt. Net als bij de uitvoering van de controle leidt dit echter alleen tot een negatieve beoordeling van de accountant als door gebruikers wordt ontdekt dat de jaarrekening onjuist was en als dit leidt tot schadeclaims en rechtszaken. Dit risico is weer vooral aanwezig als de jaarrekening wordt gepubliceerd, als de aandelen regelmatig worden verhandeld, als de onderneming in de belangstelling staat of wordt overgenomen en als de financiële positie van de onderneming slecht is.

Welke gevolgen heeft dit voor het gedrag van een opportunistische accountant?

Verlies van klanten heeft een negatieve invloed op de beoordeling van de accountant. Dit leidt ertoe dat de accountant geneigd zal zijn onder druk van het management fouten in de jaarrekening te accepteren. Fouten in de jaarrekening leiden echter tot een negatieve beoordeling van de accountant als ze worden ontdekt en schadeclaims of rechtszaken tot gevolg hebben. Omdat de negatieve invloed op zijn beoordeling dan ook zeer groot is, zal de accountant in gevallen waarin het risico van schadeclaims en rechtszaken groot is, geneigd zijn inzake de correctie van fouten in de jaarrekening voet bij stuk te houden, zelfs als dit zou leiden tot verlies van de klant.

De accountant zal zich dus als volgt gedragen:

1 net als bij de uitvoering van de controle, zal hij het risico inschatten dat fouten in de jaarrekening worden ontdekt en leiden tot schadeclaims en rechtszaken.

2 naarmate dit risico hoger wordt ingeschat, zal hij meer geneigd zijn inzake de correctie van fouten voet bij stuk te houden, zelfs als dit tot verlies van de klant zou leiden.

3 naarmate het risico van schadeclaims en rechtszaken lager wordt ingeschat, zal de accountant meer bereid zijn onder druk van het management fouten in de jaarrekening te accepteren. Dit is vooral het geval naarmate de klant groter is en meer adviesopbrengsten oplevert en de maatschap kleiner, omdat verlies van de klant dan meer nadelen oplevert. Ook als de accountant minder sociale vaardigheden en overtuigingskracht bezit en de 'fout' een meer subjectief karakter heeft, zal de accountant eerder geneigd zijn onder druk van het management fouten in de jaarrekening te accepteren, omdat hij dan minder in staat is het management van de juistheid van zijn opvattingen te overtuigen. 


\section{MAB}

\section{Schematische weergave gedragsmodel en verschillen met normatieve literatuur}

Het gedragsmodel kan schematisch worden weergegeven als in figuur 1

Figuur 1

- omvang onderneming

- complexiteit onderneming

- adviesmogelijkheden

- concurrentie tussen maatschappen

- openbaarheid onderneming

- handel in aandelen onderneming

- publieke belangstelling

financiële

- financiële positie onderneming

- risico overname onderneming

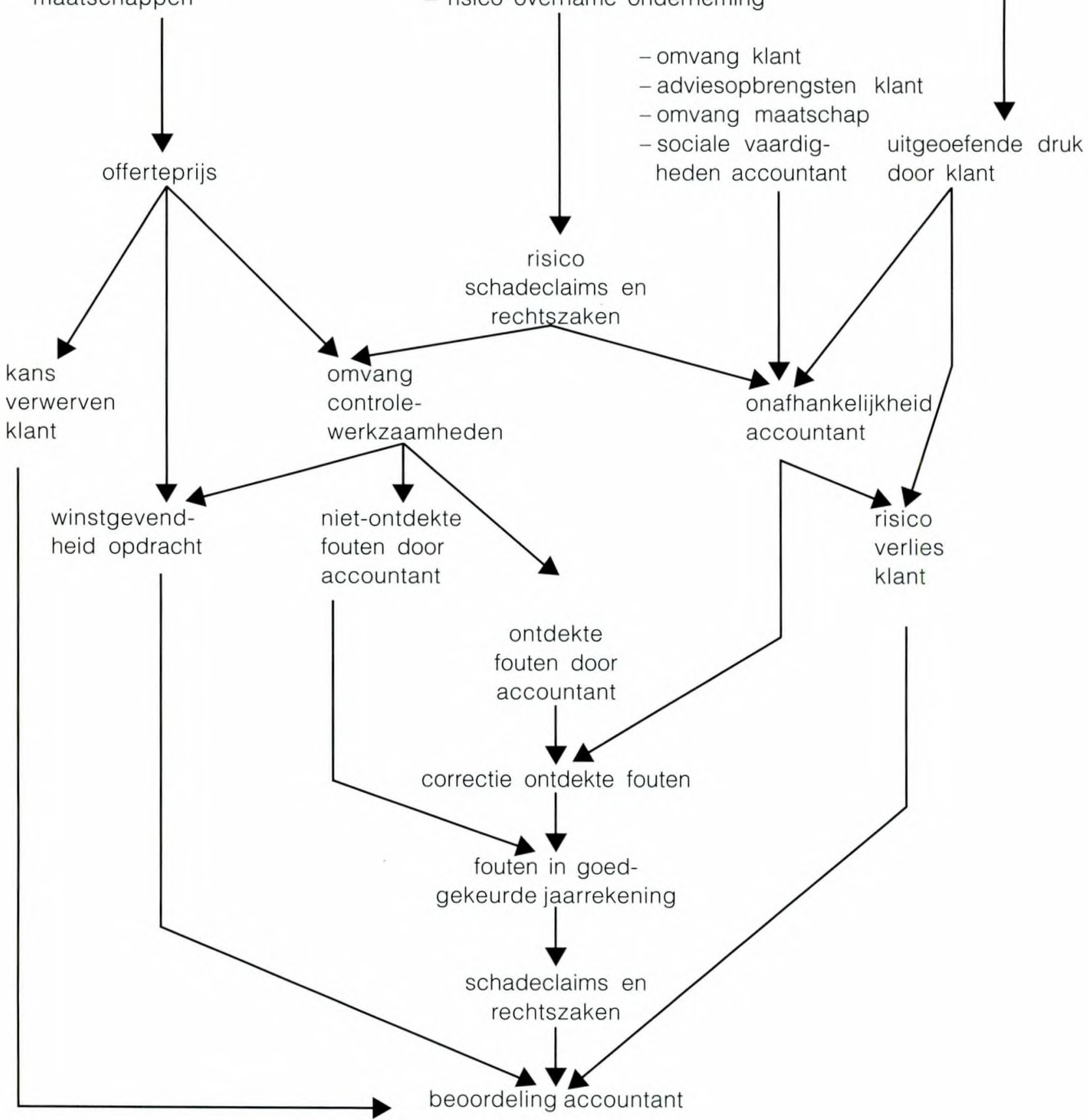




\section{MAB}

Tabel 1

\section{Normatieve literatuur}

accountants streven naar vermijding fouten in jaarrekeningen

- verwerving nieuwe klanten door goede reputatie maatschap en recommandatie

- omvang controlewerkzaamheden wordt bepaald door vaktechnische overwegingen (gericht op beperking risico dat fouten niet worden ontdekt)

- alle materiële fouten in de jaarrekening dienen gecorrigeerd te worden. Als de onderneming hiertoe niet bereid is, geeft de accountant een afkeurende verklaring

\section{Gedragsmodel}

- accountants streven naar een goede beoordeling van hun maatschap, dat wil zeggen naar:

- verwerving nieuwe klanten

- winstgevende opdrachten

- vermijden verlies bestaande klanten

- vermijden schadeclaims en rechtszaken

verwerven nieuwe klanten door uitbrengen concurrerende offertes

- omvang controlewerkzaamheden wordt bepaald door:

- met klant afgesproken prijs voor controle Jaarrekening

risico schadeclaims en rechtszaken

- onafhankelijkheid accountant wordt bepaald door o.a.:

- risico verlies klant

- nadelen bij verlies klant

- sociale vaardigheden accountant

- risico schadeclaims en rechtszaken

- uitgeoefende druk klant
Het gedragsmodel wijkt sterk af van het gedrag van accountants zoals dit in de (normatieve) literatuur wordt voorgeschreven. De belangrijkste verschillen zijn weergegeven in tabel 1.

\section{Enige empirische ondersteuning voor het gepresenteerde model}

De laatste jaren is vooral in de VS veel empirisch onderzoek gedaan naar het gedrag van accountants. Een aantal van deze onderzoeken wijzen erop dat de aspecten die in ons model worden benadrukt bij de besluitvorming van accountants vaak mede een rol spelen.

Enige voorbeelden:

- Uit diverse onderzoeken blijkt dat veel accountantsmaatschappen via een scherpe prijs- concurrentie trachten nieuwe klanten te verwerven hetgeen vaak leidt tot druk op de controlebudgetten en tot vermindering van de kwaliteit van de controle. Uit onderzoek van Bedingfield en Loeb (1974) en Shockley en Holt (1982) bleek dat de prijs die door ondernemingen voor de controle betaald dient te worden, een belangrijke factor is bij de keuze van de accountantsmaatschap. Uit onderzoek van onder meer Drieënhuizen et al (1990) en Marxen (1990) bleek dat naarmate de concurrentie tussen accountantsmaatschappen groter is, de maatschappen de neiging hebben nieuwe klanten te verwerven via het verlagen van de prijs die voor de controle in rekening wordt gebracht. Uit onderzoek van Rhode (1978), Alderman en Deitrick (1982) en Marxen (1990) bleek dat zulke prijsverlagingen vaak leiden tot een vermindering van de urenbudgetten voor de controle. ${ }^{6}$ Uit onderzoek van 


\section{MAB}

Graham (1985), Alderman en Deitrick (1982) en Kelley en Margheim (1990) bleek tenslotte dat krappe urenbudgetten vaak leiden tot beperking van de controlewerkzaamheden (vaak zelfs tot volledig nalaten van benodigde controles) en daardoor tot een vermindering van de kwaliteit van de controle.

- Verder blijkt uit diverse onderzoeken dat veel accountants onder druk van het management van de gecontroleerde onderneming bereid zijn fouten in de jaarrekening te accepteren. Zo bleek bijvoorbeeld uit onderzoek van Van de Poel en Schilder (1990) en Drieënhuizen et al (1990) dat ongeveer de helft van de onderzochte accountants onder druk van het management bereid was een duidelijk onvoldoende voorziening in de jaarrekening te accepteren

Verder blijkt dat economische overwegingen en de risico's voor de accountant zelf, een grote invloed hebben op de bereidheid van accountants om fouten in de jaarrekening te accepteren. Zo bleek uit een onderzoek van Farmer et al (1987) dat accountants tweemaal zo vaak bereid zijn fouten in de jaarrekening te accepteren als zij de indruk hebben dat hiermee verlies van de klant kan worden voorkomen en vijfmaal zo vaak als zij de indruk hebben dat het risico van schadeclaims gering is. Accountants die de indruk hadden dat door het accepteren van fouten verlies van de klant kon worden voorkomen en bovendien van mening waren dat het risico van schadeclaims gering was, bleken zelfs dertien (!) maal zo vaak bereid te zijn fouten in de jaarrekening te accepteren. Onderzoek van Knapp (1985) wijst er verder op dat de bereidheid van accountants om onder druk van het management fouten in de jaarrekening te accepteren vooral groot is als de concurrentie tussen maatschappen sterk is, als klanten veel adviesopbrengsten opleveren en als de financiële situatie van de klant goed is (waardoor het risico van schadeclaims gering is).

\section{Slotopmerkingen}

Het gepresenteerde model geeft aan hoe accountants zich zullen gedragen als zij zich uit- sluitend laten leiden door economische voordelen op korte termijn. Uiteraard zullen in de praktijk ook andere overwegingen een rol spelen zoals de reputatie van de maatschap en accountant op lange termijn. Mogelijk verschilt het belang dat wordt gehecht aan kortetermijnvoordelen respectievelijk lange-termijnoverwegingen per accountantsmaatschap en per accountant, maar dit zal nader onderzoek moeten uitwijzen.

Het gepresenteerde model verschilt sterk van de normatieve literatuur. Dit wordt vooral veroorzaakt doordat het model ervan uitgaat dat accountants naast de risico-analyse zoals beschreven in de normatieve literatuur (gericht op verminderen van het risico dat bij het uitvoeren van de controle materiële fouten niet worden ontdekt), nog een tweede risico-anaIyse toepassen, die gericht is op verminderen van het risico dat fouten in goedgekeurde jaarrekeningen nadelen opleveren voor de accountant zelf (bijvoorbeeld als gevolg van ingediende schadeclaims).

\section{Literatuur}

Alderman, C.W. and J.W. Deitrick (1982), Auditor's perceptions of time budget presures and premature sign-off: a replication and extension. Auditing: a journal of practice and theory, pp. 54-68.

Antle, R. (1984), Auditor independence, Journal of accounting research, pp. 1-20.

Bedingfield. J.P. and S.E. Loeb (1974), Auditor changes; an examination. The journal of accountancy, pp 66-69.

Blokdijk, J.H. (1989), Strategieën bij verwachtingskloven, MAB, pp. 521-527

Cook, E. and T. Kelley (1988), Auditor stress and time budgets, CPA Journal, pp. 83-86

Drieënhuizen, F. et al (1990), Exploratief onderzoek inzake 'professional judgment in de accountantspraktijk', in: Risico's en oordeelsvorming in de accountantspraktijk. Limperg Instituut.

Farmer, T.A. et al (1987), An investigation of the impact of economic and organizational factors on auditor independence, Auditing: a journal of practice and theory, pp. $1-14$

Feenstra, D.W. (1988), De beste stuurlui ...., WoltersNoordhoff

Feenstra, D.W. (1990), Empirisch onderzoek naar aspecten van de vakkundige oordeelsvorming van accountants een literatuurverkenning, in: Risico's en oordeelsvorming in de accountantspraktik, Limperg Instituut. 
Graham, L.E. (1985), Audit risk, CPA Journal, pp. 26-33

Gwilliam, D.R. (1987), A survey of auditing research, Prentice Hall.

Kelley, T. and L. Margheim (1990), The impact of time budget pressure, personality and leadership variables on dysfunctional auditor behavior, Auditing: a journal of practice and theory, pp. 21-42.

Knapp, M.C. (1985), Audit conflict: an empirical study of the perceived ability of auditors to resist management pressure, The accounting review, pp. 202-211.

Manen, J.A. van (1989), Accountantscontrole en schattingen, $M A B, p p .103-110$.

Marxen, D.E. (1990), A behavioral investigation of time budget preparation in a competitive audit environment, Accounting Horizons, pp. 47-57.

Monger, R.F. (1981), Relational characteristics and resolution modes as determinants of constructive and destructive conflict perceptions between audit firms and their clients, University of Houston.

Nichols, D.R. and K.H. Price (1976), The auditor-firm conflict: an analysis using concepts of exchange theory, The accounting review, pp. 335-346.

Parkash, M. and C.F. Venable (1993), Auditee incentives for auditor independence: the case of nonaudit services, The accounting review, pp. 113-133.

Poel, J.H.R. van de, en A. Schilder (1990), Gecontroleerd onderzoek 'Mac Frits'-casus, in: Risico's en oordeelsvorming in de accountantspraktijk, Limperg Instituut.

Rhode, J.G. (1978), Survey on the influence of selected aspects of the auditor's work environment on professional performance of certified public accountants, in: Independent auditor's work environment: a survey, AICPA.

Schwartz, K.B. and K. Menon (1985), Auditor switches bij failing firms. The accounting review, pp. 248-261.

Scott, W.R. (1984), The state of the art of academic research in auditing, Journal of accounting literature, $p p$. 153-200

Shockley, R. (1981), Perceptions of auditor's independence: an empirical analysis, The accounting review, $\mathrm{pp}$. 785-800
Shockley, R. and R.N. Holt (1982), A behavioral investigation of supplier differentiation in the market for audit services, Journal of accounting research, pp. 545-563.

St. Pierre, K. and J.A. Anderson (1984), An analysis of the factors associated with lawsuits against public accountants, The accounting review, pp. 242-263.

Wieleman, H.H.H. et al (1990), Claims en risico's in de accountantspraktijk, in: Risico's en oordeelsvorming in de accountantspraktijk, Limperg Instituut.

\section{Noten}

1 De schrijver dankt J. van Manen voor een groot aantal waardevolle opmerkingen. Ook aan K. Wezeman en enige anonieme beoordelaars is de schrijver dank verschuldigd voor hun waardevolle commentaar op een eerdere versie van dit artikel.

2 Het gunstiger voorstellen van slechte ondernemingsresultaten is ook in het belang van de eigenaren van de onderneming, omdat dit een positieve invloed heeft op de koers van de aandelen van de onderneming.

3 Zo legde Marxen (1990) aan 66 ervaren accountants een gedetailleerde beschrijving van een onderneming voor en vroeg hen een raming te maken van het aantal uren nodig voor controle van de voorraden. De ramingen liepen uiteen van 24 tot 220 uur (!).

4 Welke controles uitgevoerd zullen worden nadat een beslissing is genomen over de omvang van de controle, wordt vooral bepaald door professional judgment en valt buiten het bestek van dit artikel. Voor een overzicht van deze problematiek zie Feenstra (1990)

5 Bij minder ernstige bedenkingen kan eventueel een verklaring met beperkingen worden gegeven.

6 Zo bleek uit een onderzoek van Cook en Kelly (1988) dat $36 \%$ van de onderzochte accountants van mening was dat hun controlebudgetten zo laag waren dat ze praktisch onhaalbaar waren. 